\title{
Matrine inhibits proliferation and induces apoptosis of the androgen-independent prostate cancer cell line PC-3
}

\author{
PENG ZHANG ${ }^{1}$, ZIMING WANG ${ }^{1}$, TIE $^{\text {CHONG }}{ }^{1}$ and ZONGZHENG $\mathrm{JI}^{2}$ \\ Departments of ${ }^{1}$ Urology, and ${ }^{2}$ General Surgery, The Second Affiliated Hospital, \\ Medical School of Xi' an Jiaotong University, Xi'an, Shaanxi 710004, P.R. China
}

Received July 11, 2011; Accepted November 25, 2011

DOI: $10.3892 / \mathrm{mmr} .2011 .701$

\begin{abstract}
Current strategies to treat androgen-independent prostate cancer are associated with a number of challenges and are not yet curative. Matrine is a naturally occurring alkaloid extracted from the Chinese herb Sophora flavescens. Matrine has shown anti-proliferative properties in a number of types of cancer, including breast, gastric, lung and pancreatic tumors. Matrine was also found to promote apoptosis and inhibit invasion of cancer cells. We evaluated the antitumor effects of matrine on androgen-independent PC-3 prostate cancer cells. The effects of matrine on cell cycle progression and apoptosis of PC-3 cells were tested. Matrine-treated PC-3 cells underwent G0/G1 cell cycle arrest. There was a significant reduction in the number of $S$ phase and G2/M phase cells in the treated group when compared to untreated cells. Flow cytometry, as well as Annexin-V/PI staining, showed a significant, dose-dependent increase in the number of early, as well as late, stage apoptotic cells in matrine-treated cells compared to untreated cells. There was also an increase in the number of necrotic cells in the matrine-treated group when compared to untreated cells. Matrine treatment resulted in increased levels of caspase- 3 and Bax and decreased levels of Bcl-2. Our data suggest that matrine inhibits the proliferation of androgen-independent prostate cancer cells by causing G0/ G1 cell cycle arrest and promoting apoptosis. Matrine-induced apoptosis was mediated by downregulation of Bcl-2/Bax ratios and upregulation of caspase-3 levels. Based on our data, we suggest that matrine may be a novel addition to the current arsenal of strategies used to treat androgen-independent prostate cancer.
\end{abstract}

Correspondence to: Dr Peng Zhang, Department of Urology, Second Affiliated Hospital of Medical College of Xi'an, JiaoTong University, Xi'an, Shaanxi 710004, P.R. China

E-mail: zpbill@126.com.cn

Key words: matrine, cell cycle, apoptosis, prostate cancer, androgen-independent

\section{Introduction}

Prostate cancer is the most common cancer of the male urogenital system in the US, and the second leading cause of cancer-related mortality, accounting for almost $28 \%$ of the cancer-related mortality in 2010 (1). Although the incidence of prostate cancer in Asia is low, prolongation of the life span, environmental factors and more efficient diagnostic techniques have resulted in a recent increase in the prevalence of prostate cancer in China $(2,3)$. Prostate cancer now ranks third in China among cancers of the urogenital system, after bladder and kidney cancers (2).

The molecular pathogenesis of prostate cancer remains to be elucidated. However, the advent of improved screening techniques for prostate-specific antigen (PSA) has facilitated earlier diagnosis and the opportunity to initiate treatment earlier than was previously possible (4). Almost two-thirds of prostate cancer patients are asymptomatic at the early stages and often present to the clinic at stages $\mathrm{C}$ or D. Although radical prostatectomy and local radical radiotherapy are accepted treatments in the early stages of prostate cancer, half of these patients may experience recurrence and/or metastasis (5).

In early-stage prostate cancer, androgens are the major regulators of cellular proliferation, and tumor growth is androgen-dependent (6). The treatment of choice for these patients, who are not suitable for surgical intervention, is androgen deprivation treatment (ADT) (7). However, ADT has been reported to have long-term adverse effects (8). ADT is also not curative and the cancer recurs as a metastatic and androgen-independent tumor in approximately $70-80 \%$ of the patients (9). Androgen-independent prostate cancer is thought to result from a number of factors such as genetic instability, inactivation of detoxifying enzymes, such as GST- $\gamma$, activation of certain oncogenes or amplification of the androgen receptor (AR) (10). Current treatment for such tumors includes docetaxel-based chemotherapy, which only offers a survival advantage of 3 months and is not curative $(11,12)$. Other treatment options for androgen-independent prostate cancer include brachytherapy (13), cryotherapy and high intensity focused ultrasound treatment (14), radio-frequency ablation (15), chemotherapy $(16,17)$, angiogenic inhibitor treatment (18), gene therapy (19), immunotherapy (16) and tumor vaccine treatment (20). The goal of these treatments is to inhibit the growth of prostate cancer cells, promote apoptosis, inhibit 
angiogenesis and enhance the immune function to result in the elimination of cancer cells. Treatment of androgenindependent prostate cancer has therefore become a significant focus of recent research and it is imperative to explore novel therapeutic modalities in the treatment of such tumors.

Matrine (dodecahydro-3a,7a,diaza-benzo(de)anthracen-8-one) is an alkaloid extracted from a traditional Chinese herb (Sophora flavescens Ait.) (21). The pharmacological effects of matrine have been extensively documented in viral hepatitis $(21,22)$, cardiac arrhythmia (23) and atopic dermatitis (24). The antitumor activity of matrine has also been recently documented. Matrine has been reported to inhibit proliferation and induce apoptosis in breast (25), pancreatic (26), hepatoma (27) and lung cancer (28), and cervical cancer cells (29). The mechanisms underlying the antitumor effect of matrine have been extensively investigated. At the molecular level, matrine was reported to regulate apoptotic pathways by modulating the Bcl-2/Bax ratio (26) as well as by modulating the expression levels of Fas/FasL members (30), p53 and pRb (31) and C-myc (32). Although matrine has been used clinically in recent years to treat a number of types of cancer, the therapeutic efficacy of matrine in prostate cancer remains poorly understood.

In the present study, we investigated the effect of matrine on the androgen-independent prostate cancer cell line PC-3. We evaluated cell proliferation, cell cycle and apoptosis in order to explore the mechanisms underlying the antitumor activity of matrine on these cells. Our study aimed to provide new strategies for the clinical treatment of androgen-independent prostate cancer.

\section{Materials and methods}

Cell culture and reagents. The androgen-independent, human prostate cancer cell line PC-3 was provided by the Molecular Biology Laboratory, School of Medicine of the Xi'an Jiaotong University, China. This cell line was derived from the bone metastatic foci of a 62-year-old Caucasian patient with prostate cancer. PC-3 cells exhibit low level activity of acid phosphatase and $5 \alpha$-reductase. They do not produce PSA or express AR. PC-3 cells were maintained in RPMI-1640 complete medium containing $10 \%$ inactivated fetal calf serum, $100 \mathrm{U} /$ $\mathrm{ml}$ penicillin and $100 \mathrm{U} / \mathrm{ml}$ streptomycin. The cell culture reagents including media, serum and antibiotics were all purchased from Gibco (Invitrogen, Carlbad, CA, USA). Cell cultures were maintained at $37^{\circ} \mathrm{C}$ in the presence of $5 \% \mathrm{CO}_{2}$. Bcl-2, Bax antibodies were purchased from Boshide, Wuhan, China.

Western blot analysis. Protein extracts from untreated and matrine-treated cells were separated on SDS-PAGE and transferred to polyvinylidene fluoride (PVDF) membranes. Membranes were blocked and then incubated with mouse antihuman Bcl-2, or Bax monoclonal antibody (1:1000 dilution), mouse anti-human caspase-3 antibody or mouse anti-human $\beta$-actin polyclonal antibody (1:5000). Membranes were washed extensively and then incubated with horseradish peroxidaseconjugated goat anti-mouse $\operatorname{IgG}(1: 1000)$. The optical density of bands was analyzed with Quantitive One software (BioRad, CA, USA).
Cell cycle characterization and cell death analysis. Cell cycle analysis was performed with PC-3 cells, which were seeded in a 24 -well plate at a density of $5 \times 10^{5}$ cells/well. The cells were treated with matrine for the specified time periods and harvested. Untreated and treated cells were fixed in $75 \%$ pre-chilled ethanol $\left(-20^{\circ} \mathrm{C}\right)$ overnight at $4^{\circ} \mathrm{C}$, resuspended in PI buffer (50 g/l PI and $15 \mathrm{~g} / 1 \mathrm{RNase})$ and incubated at room temperature for $20 \mathrm{~min}$ in the dark. Cells were then washed twice ( 3 min each wash) with PBS and subjected to flow cytometry $\left(10^{4}\right.$ cells/sample) (FASCalibur from FALS CALIBAR BD, USA). The excitation wavelength was $488 \mathrm{~nm}$ and the red fluorescence was collected through a $630 \mathrm{~nm}$ longpass filter. DNA analysis was performed with FACSort Cell Quest software (BD, USA).

Apoptosis was evaluated using the Annexin V/FITC Apoptosis Detection kit from BD, USA.PC-3 cells were seeded in a 24 -well plate $\left(5 \times 10^{5}\right.$ cells/well $)$ and cultured at $37^{\circ} \mathrm{C}$ in a humidified atmosphere with $5 \% \mathrm{CO}_{2}$ for $4 \mathrm{~h}$. The medium was then replaced with fresh matrine solution at various concentrations (100 $\mu 1 /$ well), supplemented with RPMI-1640 complete medium (the final volume in each well was $2 \mathrm{ml}$ ) and incubation was carried out at $37^{\circ} \mathrm{C}$ in a humidified atmosphere for $24 \mathrm{~h}$. Cells were harvested and centrifuged twice at $1000 \mathrm{rpm}$ ( 5 min each spin). The cells were washed twice in binding buffer ( 3 min each), resuspended in $1 \mathrm{ml}$ of binding buffer, $5 \mu \mathrm{l}$ of Annexin V-FITC and $5 \mu \mathrm{l}$ of PI and incubated in the dark at room temperature for $15 \mathrm{~min}$. Flow cytometry was performed with an excitation wavelength of $488 \mathrm{~nm}$. The FACSort Cell Quest software (BD, USA) was used for DNA analysis. Scatter plots were delineated based on the FITC fluorescence and PI fluorescence. The scatter plot was divided into four quadrants: left lower quadrant: Annexin V-FITC(-) and PI(-) represents viable cells; left upper quadrant: Annexin V-FITC(-) and $\mathrm{PI}(+)$ represents necrotic cells; right lower quadrant: Annexin V-FITC(+) and PI(-) represents early apoptotic cells; right upper quadrant: Annexin V-FITC(+) and $\mathrm{PI}(+)$ represents late apoptotic cells.

Statistical analysis. Data are expressed as the mean with standard deviation. The one-way ANOVA with Bonferroni adjustments for post-hoc tests was performed for comparisons between groups. The Spearman correlation coefficient (@) was performed to test the dose-dependence between matrine doses and other variables. Statistical analyses were set with a significance level of 0.05 and performed with SPSS ${ }^{\circledR}$ version 15.0 statistical software (SPSS, Chicago, IL, USA).

\section{Results}

Cell cycle. PC-3 cells treated with $25,50,75$ or $100 \mathrm{mg} / \mathrm{l}$ of matrine showed a significant increase in the percentage of $\mathrm{G}_{0} / \mathrm{G}_{1}$ phase cells compared with the untreated control cells (Fig. 1). This was accompanied by a significant decrease in the percentages of $S$ and $\mathrm{G}_{2} / \mathrm{M}$ phase cells in all four treatment groups when compared with the control cells. There was also a significant, dose-dependent increase in the percentage of apoptotic cells in all four treatment groups when compared to untreated cells. Cells treated with $50 \mathrm{mg} / \mathrm{l}$ of matrine had a significantly higher number of apoptotic cells compared to the $25 \mathrm{mg} / \mathrm{l}$ and control groups, while the $75 \mathrm{mg} / \mathrm{l}$ and the 


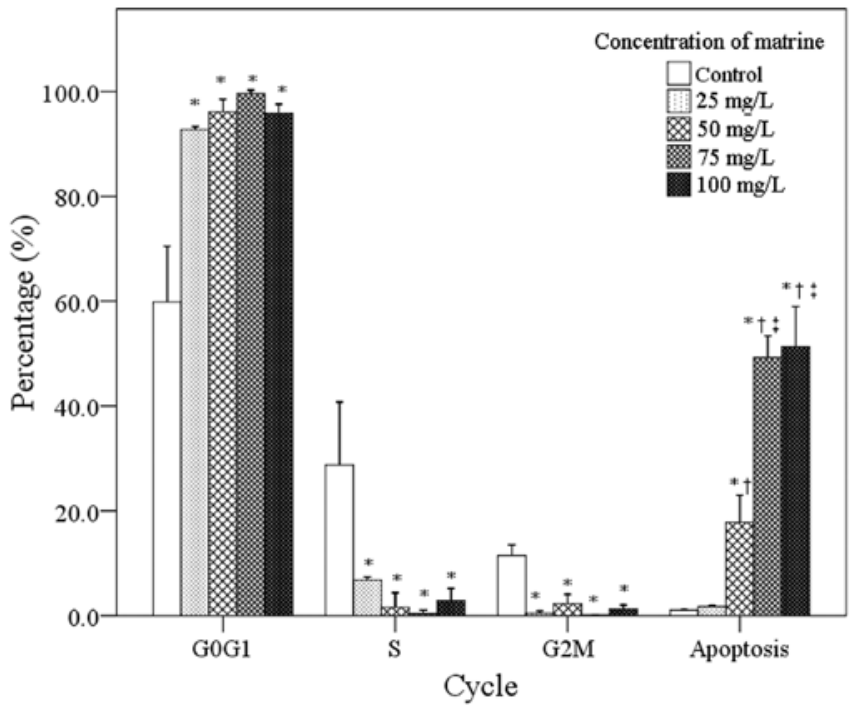

Figure 1. Summary of cell cycle distribution in matrine-treated PC-3 cells. *Indicates a significant difference compared to the control group. Indicates a significant difference compared to the matrine $25 \mathrm{mg} / \mathrm{L}$ group. ${ }^{+}$Indicates a significant difference compared to the matrine $50 \mathrm{mg} / \mathrm{L}$ group.

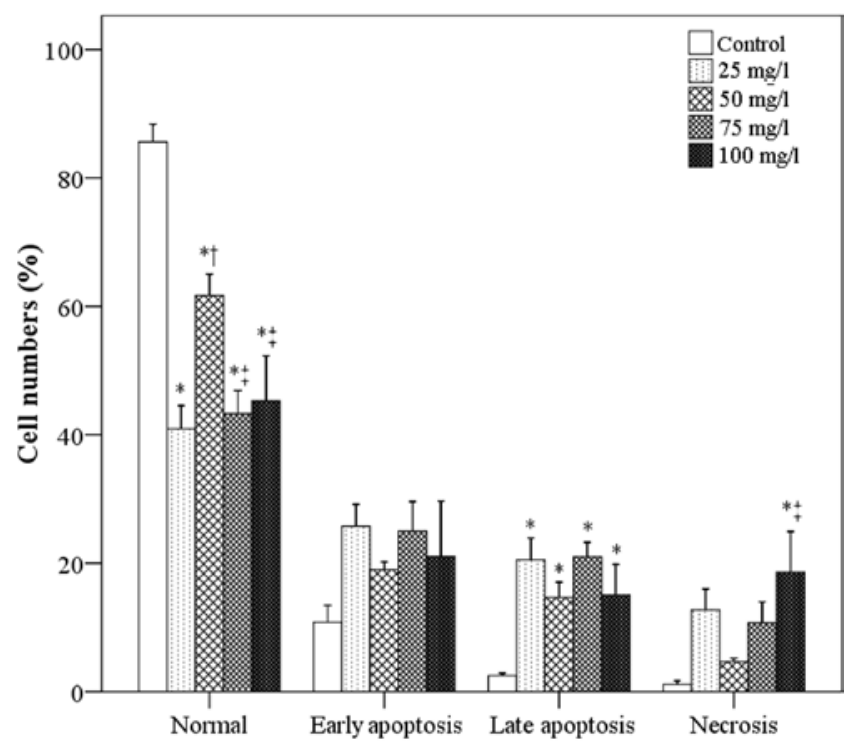

Figure 2. Summary of Annexin V/PI analysis of matrine-treated PC-3 cells. *Indicates a significant difference compared to the control group. Indicates a significant difference compared to the matrine $25 \mathrm{mg} / \mathrm{L}$ group. ${ }^{+}$Indicates a significant difference compared to the matrine $50 \mathrm{mg} / \mathrm{L}$ group.

$100 \mathrm{mg} / \mathrm{l}$ groups had significantly higher numbers of apoptotic cells compared to the $50 \mathrm{mg} / \mathrm{l}$ group (Fig. 1).

Annexin V/PI analysis. We used the Annexin V/PI assay to evaluate apoptosis in matrine-treated PC-3 cells. A significant increase was noted in the number of late apoptotic cells in the four treatment groups when compared to the untreated cell groups $(20.5,14.6,21.0,15.1$ vs. $2.5 \%)$. Notably, the number of necrotic cells was also higher in the $100 \mathrm{mg} / \mathrm{l}$ matrine-treated group when compared to the $50 \mathrm{mg} / \mathrm{l}$ group and untreated cells (18.6 vs. 4.7 and $1.1 \%$ respectively).

The percentage of normal cells was significantly lower in the four matrine-treated groups when compared to the control
A

\begin{tabular}{lllll}
\multicolumn{5}{c}{ Matrin (mg/L) } \\
\hline 0 & 25 & 50 & 75 & 100
\end{tabular}

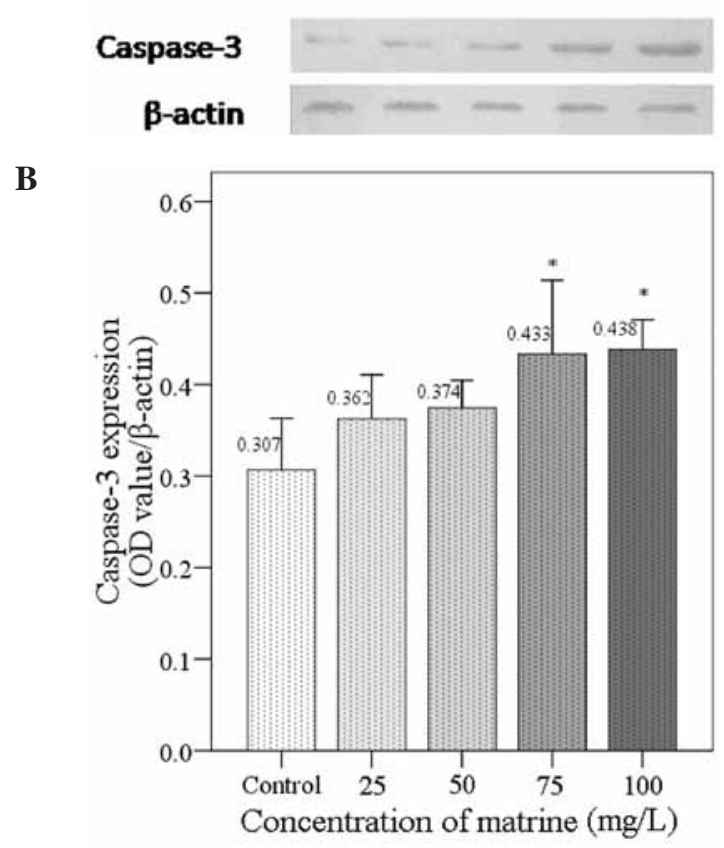

Figure 3. Analysis of caspase-3 expression in matrine treated PC-3 cells. (A) Western blot analysis of caspase-3 expression in matrine-treated PC-3 cells. (B) Quantitation result of caspase-3 expression levels by densitometer using beta-actin as internal control. *Indicates a significant difference compared to the control group.

group $(41.0,61.7,43.3,45.3$ vs. $85.6 \%)$. The percentage of normal cells was significantly higher in the matrine $50 \mathrm{mg} / \mathrm{l}$ group when compared to the $25 \mathrm{mg} / \mathrm{l}$ group. However, the matrine $75 \mathrm{mg} / \mathrm{l}$ and $100 \mathrm{mg} / \mathrm{l}$ groups had significantly lower numbers of normal cells when compared with the $50 \mathrm{mg} / \mathrm{l}$ group (Fig. 2).

Caspase-3. We used Western blotting to evaluate the expression of caspase-3 levels in untreated and matrine-treated PC-3 cells (Fig. 3). Matrine treatment resulted in an increase in caspase-3 protein levels (Fig. 3A). Quantitation of the bands showed a dose-dependent increase in the level of caspase-3 (from 0.307 to 0.438 ). There was a significantly higher expression of caspase- 3 in the 75 and $100 \mathrm{mg} / \mathrm{l}$ matrine treatment groups compared to the control group ( 0.433 and 0.438 vs. 0.307) (Fig. 3B).

Bax and Bcl-2. Using Western blotting, we showed that PC-3 cells treated with increasing concentrations of matrine, exhibited an increase in the levels of Bax and a decrease in the levels of Bcl-2 (Fig. 4A). Quantitation of the bands showed a dose-dependent increase in the expression of Bax in the four matrine treatment groups (from 0.28 to 0.39 ; $\mathrm{Q}=0.672$; $\mathrm{p}<0.001)$. PC-3 cells treated with 75 or $100 \mathrm{mg} / \mathrm{l}$ of matrine showed significantly higher levels of Bax when compared to the control and $25 \mathrm{mg} / \mathrm{l}$ matrine-treated groups $(0.37$ and 0.39 vs. 0.28 and 0.31 ). The $100 \mathrm{mg} / 1$ matrine treatment group exhibited significantly higher levels of Bax than the matrine $50 \mathrm{mg} / \mathrm{l}$ group (0.39 vs. 0.33). 


\section{$\operatorname{Matrin}(\mathbf{m g} /$ L)}

\section{$\begin{array}{lllll}0 & 25 & 50 & 75 & 100\end{array}$}
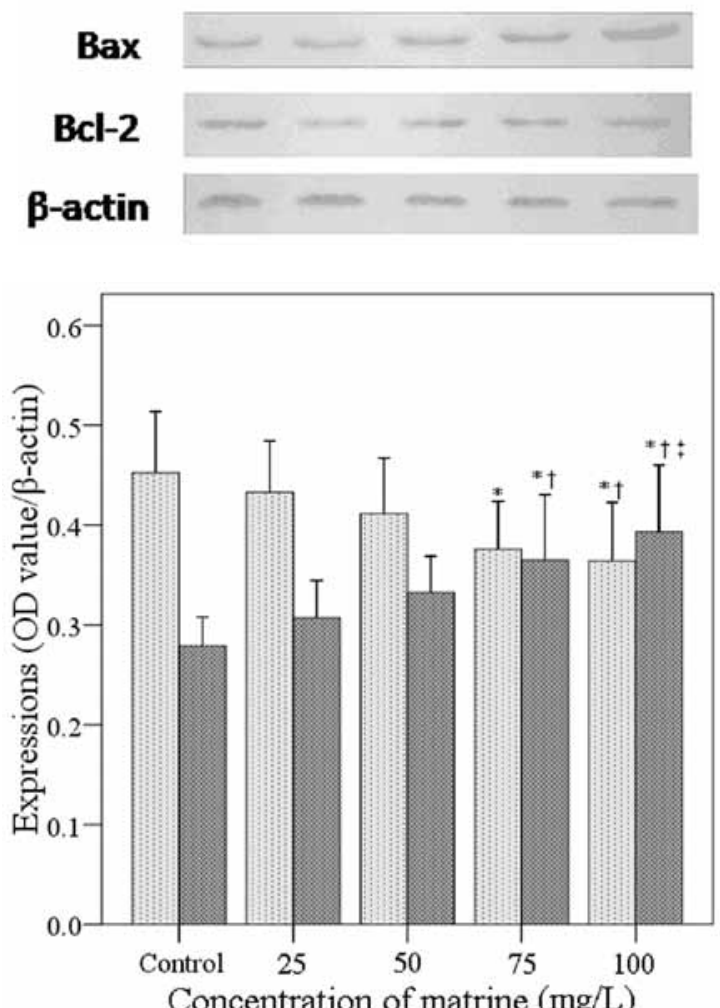

Bcl-2 expression (OD value/ $\beta$-actin) Bax expression (OD value/ $\beta$-actin)

Figure 4. Analysis of Bcl-2 and Bax protein expression in matrine treated PC-3 cells. (A) Western blot analysis of Bcl-2, top penel, and Bax, middle panel, expression in matrine-treated PC-3 cells. Beta-actin was used as loading control. (B) Quantitation of Bax and Bcl-2 expression levels by densitometer using beta-actin as internal control. "Indicates a significant difference compared to the control group. Indicates a significant difference compared to the matrine $25 \mathrm{mg} / \mathrm{L}$ group, ${ }^{\ddagger}$ Indicates a significant difference compared to the matrine $50 \mathrm{mg} / \mathrm{L}$ group.

By contrast, there was a dose-dependent decrease in the levels of Bcl-2 in the four matrine-treatment groups $(\varrho=-0.493$, $\mathrm{P}<0.001)$. The $75 \mathrm{mg} / \mathrm{l}$ and $100 \mathrm{mg} / \mathrm{l}$ treatment groups had significantly lower levels of Bcl-2 when compared with the control group (0.38 and 0.36 vs.0.45) and the $100 \mathrm{mg} / 1$ treatment group had significantly lower Bcl-2 expression compared to the $25 \mathrm{mg} / \mathrm{l}$ group (0.36 vs. 0.43 ) (Fig. 4).

\section{Discussion}

In this study, we evaluated the antitumor effect of the naturally occurring alkaloid, matrine, on an androgen-independent prostate cancer cell line. We used flow cytometry to show that PC-3 cells treated with matrine were arrested at the G0/G1 phase of the cell cycle. We also used Annexin-V/PI staining to show a significantly higher number of apoptotic cells in the matrine-treated group compared to the untreated group. Matrine-treated PC-3 cells showed upregulation of the proapoptotic protein Bax, and downregulation of the anti-apoptotic protein $\mathrm{Bcl}-2$. Our data provide a mechanistic basis for the development of a novel strategy to treat androgen-resistant prostate cancer.

There are numerous drawbacks to the existing prostate cancer treatment strategies, making treatment of androgen-independent prostate cancer a challenge. Although chemotherapy is used to debulk the tumor, it is not curative. Additionally, the adverse effects observed with chemotherapy and radiotherapy compromise tolerability. The use of angiogenesis inhibitors results in impaired repair processes. The transfection efficiency, in vivo expression of the target gene and selection of vectors and safety are factors that have not been validated in gene therapy. Immunotherapy is dependent on the immune response of the host. Novel treatment strategies, which are capable of overcoming such drawbacks, are therefore urgently required.

The antitumor effects of matrine have been previously demonstrated in a number of types of cancer $(25-27,29)$. Matrine was previously reported to inhibit proliferation of tumor cells by causing cell cycle arrest at the G0/G1 or S-phase $(25,27,32,33)$, Evaluation of cell proliferation using PCNA or Ki-67 also showed a significant decrease in proliferation in matrine-treated cells (26). Our data agreed with these reports and showed that PC-3 cells treated with matrine were arrested at the G0/G1 phase of the cell cycle. The length of the cell cycle is predominantly determined by the $G_{0} / G_{1}$ phase and cell cycle arrest at this stage would therefore result in slower proliferation. We showed a dose-dependent increase in the number of G0/G1 cells in the matrine-treated group when compared to untreated cells, accompanied by decreased proportions of cells in the $\mathrm{S}$ and $\mathrm{G}_{2} / \mathrm{M}$ phases.

The antitumor effects exerted by a number of Chinese medicines have been shown to be mediated via induction of apoptosis. The complex, multistep, apoptotic pathway is orchestrated by interactions between a large number of pro- and anti-apoptotic proteins such as Bcl-2, Bcl-xl, Mcl-1, Bax and Bak, among others (34). It has been suggested that pro-apoptotic Bax is sequestered by the anti-apoptotic Bcl-2 and is activated/liberated by specific apoptotic signals to initiate the apoptotic cascade (34). Mechanistic studies have shown that matrine-mediated apoptosis was accompanied by reduced $\mathrm{Bcl}-2 / \mathrm{Bax}$ ratios and upregulation in caspase 3,8 and 9 expression levels in a number of different cancer cell types $(26,27,35,36)$. In addition to causing $\mathrm{S}$-phase cell cycle arrest and reducing the $\mathrm{Bcl}-2 / \mathrm{Bax}$ ratio in breast cancer cells, matrine also inhibited invasion of breast cancer cells (25). Notably, matrine was shown to induce autophagy in human hepatoma cells (27).

In the present study, we used AnnexinV/PI staining to show a significant, dose-dependent increase in the number of early as well as late apoptotic cells in matrine-treated PC-3 cells when compared to untreated cells. We evaluated the mechanism underlying matrine-induced apoptosis of PC-3 cells by looking at the expression levels of key proand anti-apoptotic proteins. Our data showed a significant, dose-dependent upregulation in the levels of caspase-3 following $24 \mathrm{~h}$ of treatment with matrine, suggesting that apoptosis is mediated via the mitochondria-cytochrome C/caspase-9/caspase-3 pathway. We evaluated the Bcl-2/ Bax ratio in matrine-treated cells and showed a significant upregulation in Bax levels and a significant downregulation 
in $\mathrm{Bcl}-2$ levels in $\mathrm{PC}-3$ cells treated with matrine, when compared to control cells.

Of note, we also showed increased necrosis in PC-3 cells treated for prolonged periods of time with high doses of matrine. Matrine was previously reported to cause widespread necrosis, in addition to apoptosis in hepatocellular carcinoma tumor-bearing mice treated with matrine (37). It will be interesting to more completely understand the mechanisms underlying cell death decisions mediated by matrine.

Some significant limitations of our study are that we only evaluated the effect of matrine on one androgen-independent prostate cancer cell line. We aim to validate our results using additional androgen-independent prostate cancer cell lines. We would also like to evaluate the effect of matrine on adhesion and invasion of prostate cancer cells. It will be interesting to establish xenografts from androgen-independent prostate cancer cell lines and to evaluate the effect of matrine in these tumor-bearing mice. It is crucial to understand the mechanisms underlying the anti-proliferative effects of matrine in vivo.

In conclusion, we showed that the naturally occurring alkaloid matrine had an anti-proliferative effect on androgenindependent prostate cancer cells. To the best of our knowledge, we are the first to show that matrine induces a G0/G1 cell cycle arrest and mediates apoptosis via upregulation of caspase-3 and downregulation of the Bcl-2/Bax ratio in PC-3 cells. Our data help clarify the anti-proliferative mechanisms of matrine and open new avenues in the treatment of prostate cancer.

\section{References}

1. Jemal A, Siegel R, Xu J and Ward E: Cancer statistics, 2010. CA Cancer J Clin 60: 277-300, 2010.

2. Pu YS, Chiang HS, Lin CC, Huang CY, Huang KH and Chen J: Changing trends of prostate cancer in Asia. Aging Male 7: 120-132, 2004

3. Dai B, Kong YY, Ye DW, Ma CG, Zhou XY and Yao XD: Human epidermal growth factor receptor type 2 protein expression in Chinese metastatic prostate cancer patients correlates with cancer-specific survival and increases after exposure to hormonal therapy. Asian J Androl 10: 701-709, 2008.

4. Kohli $M$ and Tindall DJ: New developments in the medical management of prostate cancer. Mayo Clin Proc 85: 77-86, 2010

5. Damber JE and Aus G: Prostate cancer. Lancet 371: 1710-1721, 2008.

6. Feldman BJ and Feldman D: The development of androgen-independent prostate cancer. Nat Rev Cancer 1: 34-45, 2001.

7. Quon H and Loblaw DA: Androgen deprivation therapy for prostate cancer - review of indications in 2010. Curr Oncol 17 Suppl 2: S38-S44, 2010.

8. Klotz L: Hormone therapy for patients with prostate carcinoma. Cancer 88: 3009-3014, 2000.

9. Gioeli D: Signal transduction in prostate cancer progression. Clin Sci (Lond) 108: 293-308, 2005.

10. Heidenreich A, von Knobloch R and Hofmann R: Current status of cytotoxic chemotherapy in hormone refractory prostate cancer. Eur Urol 39: 121-130, 2001.

11. Petrylak D: Therapeutic options in androgen-independent prostate cancer: building on docetaxel. BJU Int 96 (Suppl 2): 41-46, 2005.

12. Sartor AO: Progression of metastatic castrate-resistant prostate cancer: impact of therapeutic intervention in the post-docetaxel space. J Hematol Oncol 4: 18, 2011.

13. Marcus DM, Jani AB, Godette K and Rossi PJ: A review of low-dose-rate prostate brachytherapy - techniques and outcomes. J Natl Med Assoc 102: 500-510, 2010.
14. Singh J, Trabulsi EJ and Gomella LG: Is there an optimal management for localized prostate cancer? Clin Interv Aging 5: 187-197, 2010.

15. Lecornet E, Ahmed HU, Moore $\mathrm{CM}$ and Emberton M: Conceptual basis for focal therapy in prostate cancer. J Endourol 24: 811-818, 2010.

16. Kim SJ and Kim SI: Current treatment strategies for castrationresistant prostate cancer. Korean J Urol 52: 157-165, 2011.

17. Di Lorenzo G, Buonerba $C$ and Kantoff PW: Immunotherapy for the treatment of prostate cancer. Nat Rev Clin Oncol 8: 551-561, 2011.

18. Yu EM, Jain M and Aragon-Ching JB: Angiogenesis inhibitors in prostate cancer therapy. Discov Med 10: 521-530, 2010.

19. Dash R, Azab B, Shen XN, et al: Developing an effective gene therapy for prostate cancer: New technologies with potential to translate from the laboratory into the clinic. Discov Med 11: 46-56, 2011.

20. Pienta KJ and Smith DC: Advances in prostate cancer chemotherapy: a new era begins. CA Cancer J Clin 55: 300-318, 2005.

21. Liu J, Zhu M, Shi R and Yang M: Radix Sophorae flavescentis for chronic hepatitis B: a systematic review of randomized trials. Am J Chin Med 31: 337-354, 2003.

22. Long Y, Lin XT, Zeng KL and Zhang L: Efficacy of intramuscular matrine in the treatment of chronic hepatitis $\mathrm{B}$ Hepatobiliary Pancreat Dis Int 3: 69-72, 2004.

23. Zhang BH, Wang NS, Li XJ, Kong XJ and Cai YL: [Antiarrhythmic effects of matrine]. Zhongguo Yao Li Xue Bao 11: 253-257, 1990 (In Chinese).

24. Liu JY, Hu JH, Zhu QG, Li FQ, Wang J and Sun HJ: Effect of matrine on the expression of substance $\mathrm{P}$ receptor and inflammatory cytokines production in human skin keratinocytes and fibroblasts. Int Immunopharmacol 7: 816-823, 2007.

25. Yu P, Liu Q, Liu K, Yagasaki K, Wu E and Zhang G: Matrine suppresses breast cancer cell proliferation and invasion via VEGF-Akt-NF-kappaB signaling. Cytotechnology 59: 219-229, 2009.

26. Liu T, Song Y, Chen H, Pan S and Sun X: Matrine inhibits proliferation and induces apoptosis of pancreatic cancer cells in vitro and in vivo. Biol Pharm Bull 33: 1740-1745, 2010.

27. Zhang JQ, Li YM, Liu T, et al: Antitumor effect of matrine in human hepatoma $\mathrm{G} 2$ cells by inducing apoptosis and autophagy. World J Gastroenterol 16: 4281-4290, 2010.

28. Zhang Y, Zhang H, Yu P, et al: Effects of matrine against the growth of human lung cancer and hepatoma cells as well as lung cancer cell migration. Cytotechnology 59: 191-200, 2009.

29. Zhang L, Wang T, Wen X, et al: Effect of matrine on HeLa cell adhesion and migration. Eur J Pharmacol 563: 69-76, 2007.

30. Dai ZJ, Gao J, Ji ZZ, et al: Matrine induces apoptosis in gastric carcinoma cells via alteration of Fas/FasL and activation of caspase-3. J Ethnopharmacol 123: 91-96, 2009.

31. Zhu P, Chen JM, Chen SZ, et al: Matrine inhibits vascular smooth muscle cell proliferation by modulating the expression of cell cycle regulatory genes. Acta Pharmacol Sin 31: 1329-1335, 2010.

32. Chen Q, Liu L and Cao H: [Effects of matrine on the growth inhibition, c-myc and hTERT protein expression in human adenocarcinoma lung cancer cell line A549.]. Zhongguo Fei Ai Za Zhi 11: 559-562, 2008 (In Chinese).

33. Li Y, Wang B, Zhou C and Bi Y: Matrine induces apoptosis in angiotensin II-stimulated hyperplasia of cardiac fibroblasts: effects on Bcl-2/Bax expression and caspase-3 activation. Basic Clin Pharmacol Toxicol 101: 1-8, 2007.

34. Ghiotto F, Fais F and Bruno S: BH3-only proteins: the death-puppeteer's wires. Cytometry A 77: 11-21, 2010.

35. Han Y,Zhang S, Wu J, et al: Matrine induces apoptosis of human multiple myeloma cells via activation of the mitochondrial pathway. Leuk Lymphoma 51: 1337-1346, 2010.

36. Qin XG, Hua Z, Shuang W, Wang YH and Cui YD: Effects of matrine on HepG2 cell proliferation and expression of tumor relevant proteins in vitro. Pharm Biol 48: 275-281, 2010.

37. Ma LD, Zhang Y, Wen SH, et al: [Inhibition of tumor growth in tumor-bearing mice treated with matrine]. Zhonghua Zhong Liu Za Zhi 27: 339-341, 2005 (In Chinese). 